\title{
Two Days of the Wheels of the Horizontal Angle Change Impact Study of 12 Type Rack Pumping Unit Frame
}

\author{
Xiao-hua Li, Song-tao Jiu \\ Southwest Petroleum University, Chengdu 610500
}

\begin{abstract}
With the continuous progress of the oil production technology, the pumping uniform the original beam pumping unit has gradually developed into a non-beam pumping unit. Long annular rack pumping unit is a kind of non-beam pumping unit. Studyingfor the overall stress of the 12 type long ring rack pumping unit, when the diameter of the up sky wheel is equal to the diameter of the beforesky wheel. The influence of the angle between the connecting line and the horizontal plane on the whole stress state, deformation and stability of the frame is two sky wheel.According to the basic parameters of t-he oil machine type 12 long ring gear rack pumping determined the pumping unit's overall size, then carries on the stress analysis to the wheel for two sky wheel, for horizontal and vertical component of their respective,using SolidWorks to 12 long ring rack pumping oil machine modeling, then will be built model were introduced into ANSYS Workbench. Finally to mesh, applied load, fixed constraint, solve with the model. As can be seen from the results, when the two days of the wheel core connection and the angle between the horizontal plane changes, it will cause the overall stability of the rack, stress, deformation, strength, etc. With the increase of the angle, the equivalent stress and total deformation of the frame will be increased, and the stability of the frame will be reduced.
\end{abstract}

Keywords: Rack; Wheels day; Induded angle; Stability; Equivalent stress ;Deformation

\section{Introduction}

In the process of oil exploitation, the oil recovery methods are divided from the spray oil and mechanical oil recovery method. Flowing production is according to the strata pressure to the exploitation of crude oil itself. Mechanical recovery method is in the driving of the pumping unit, through the rod drives the pump up and down reciprocating motion, the flowing ability of mechanical oil production is realized. Currently, most of the domestic and international oil application method is mechanical recovery method.

Pumping unit is mainly divided into be-am and non-beam two categories.Beam p-umping unit has a simple structure, high reliability, durability, use, easy maintenance and so on.However, as many oil gradually into the late mining, oil well water rising, declining fluid level, conventional beam pumping unit can not meet the requirements, and thus began a non-beam pumping unit. No beam pumping of rapid development in our country, made a number of new non-beam long stroke pumping unit.New long-stroke hydraulic non-beam pumping unit can effectively control the speed of the pump and sucker rod pumping motion up and down stroke, the stroke and the stroke rate can be adjusted as needed, strong adaptability. Increasing the pump displacement factor and full coefficient, help to increase oil production and lower production costs; long stroke and low speed, smooth movement, the dynamic load is small, can increase the service life of the whole pumping equipment. Increase from the pumping unit has a balanced approach is simple, easy to adjust the balance pumping unit, pumping simple structure, light weight, small footprint, it can increase pump efficiency and increase oil production.Chai-n pumping unit has a long stroke, high oil pumping efficiency, more uniform pumping motion, the smaller peak load range and variation.In recent years, in view of the existing various pumping unit is difficult to simultaneously meet the requirements of high reliability and good energy saving effect of the status quo, we developed a lo-ng annular rack pumping unit.

\section{Long annular rack pumping unit structure, working principle and characteristics}

The new pumping unit use "gear - long annular rack" mechanism, By one-way rotating pinion drive long ring rack up and down, and drives the sliding block up and down reciprocating motion, so as to realize the basic pumping action. Its structure is shown in figure 1:

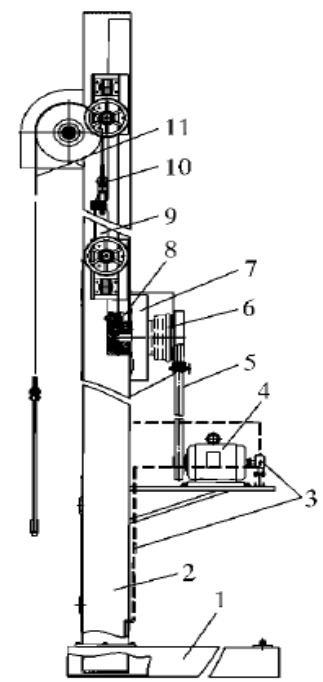

1-base;2-the fuselage;3-lubrication syst-em;4-motor;5-tape drive and brake

Volume 5 Issue 6, June 2016 www.ijsr.net 


\section{International Journal of Science and Research (IJSR) \\ ISSN (Online): 2319-7064 \\ Index Copernicus Value (2013): 6.14 | Impact Factor (2015): 6.391}

syst-em;6-reducer;7-reversing level track;8 - pinion and guide wheel;9-balance slider; 10 - suspension system;11- hanging heavy tape

Long annular rack pumping main structure of the organic base, the body, lubrication systems, motors, belt drive and braking systems, reducer, pinion, ring long rack, weights two days wheels and so on. Frame and body with a welding structure, H-shaped steel fuselage on both sides of the column is to slide the slider up and down movement of the balance, long annular rack mounted on the balance slider.

The working principle of circular rack long annular rack fixed to the balance slider, the balance slider by roller constraints on the way, so that it can move up and down; the rotation of the motor output via the belt drive to the reducer, reducer output shaft with the pinion gear and the guide wheels, while rotating the pinionand gear can guide wheels together in a horizontal direction parallel track along the horizontal movement; Pinion and the guide wheels are coaxially mounted, freely rotatable, due to limitations of the annular guide groove on the balance slider, and the annular pinion rack can always keep a go-odengagement, the pinion gear does not change the continuous rotation, the slider can be driven to achieve reciprocating motion up and down, which led to the suspension and pump achieve pumping action.

Long annular rack pumping unit is easyto realize long stroke, low red times; high reliability, smooth operation; energy; lig-ht weight, ease of maintenance and so on. Long-established and behavior analysis of 12 type rack pumping unit frame Model Long-established of 12 type rack pumping unit frame Model. The basic parameters of the 12 type rack pumping unit: Maximum rod load 120-KN, stroke $5 \mathrm{~m}$, red times $6 / \mathrm{min}$. The condition is satisfied rack according to the basic parameters of the pumping unit overall dimensions: length $\times$ width $\times$ height: $2-930 \times 1790 \times$ $13073 \mathrm{~mm}$. Two days a wheel diameter $\mathrm{D}=450 \mathrm{~mm}$. The all-welded steel frame from its overall frame structure shown in Figure 2:

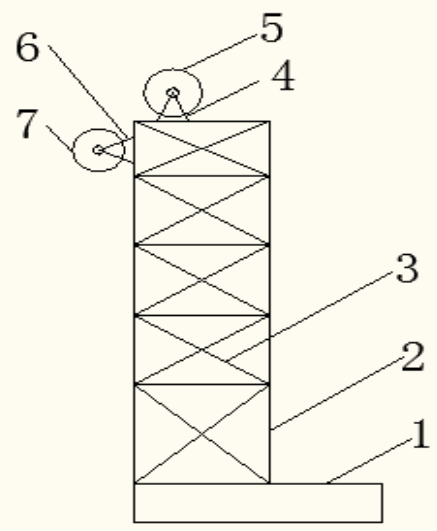

Figure 2: Frame Structure Diagram

1- base; 2 - the main stand; 3- oblique support; 4- wheel bearing heaven; heaven 5- wheel; 6- yesterday wheel bearing; 7 the day before yesterday wheel
Frame integral structure is mainly composed of the base, the main stand, sway bracing for two days and the wheel bearing and so on.Rackmounted on the base, in the upper part of the frame platform, god wheel carrier fixedly mounted on the operating platform, easy installation and maintenance, the day before the wheel bearing is installed on the wellhead and the same direction of the side rack.

According rack parameters using Solid works to establish three-dimensional model of the rack.Its chassis model shown in Figure 3.

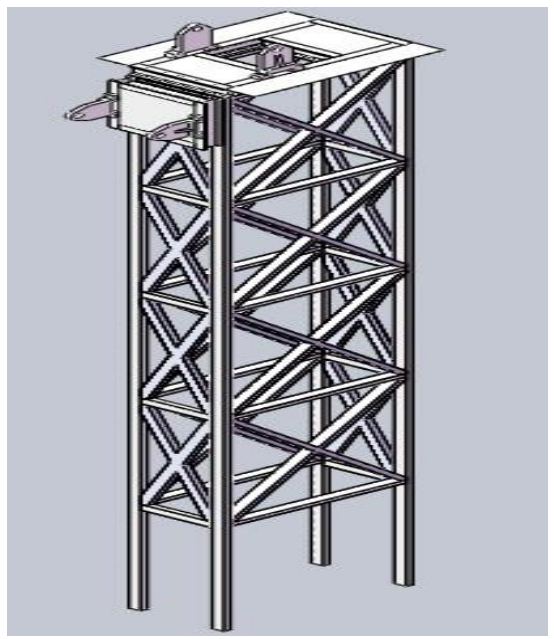

Figure 3: Frame 3 d model diagram

Rack three-dimensional model consists of four columns, diagonal bracing, the top platform and the like. Column using long $12300 \mathrm{~mm}$, cross-sectional dimensions of $1-40 \mathrm{~mm} \times 80 \mathrm{~mm}$ square steel, Oblique sup-port the use of cross-sectional dimensions of $80 \mathrm{~mm} \times 80 \mathrm{~mm}$ square steel, Top platform support welded $220 \mathrm{~mm} \times 112 \mathrm{~mm} \times 10 \mathrm{~mm}$ I-beam formed.

\section{Two days Wheel Stress Analysis}

Two days of wheel is fixed on the two days of the wheel bearing, the belt around two days on wheels, one end connected to the elongated rack, the other end connected to the beam hanger.So two days wheelis equal to the crown block, just change the direction of the force, without changing the power size. Its force shown in Figure 4:

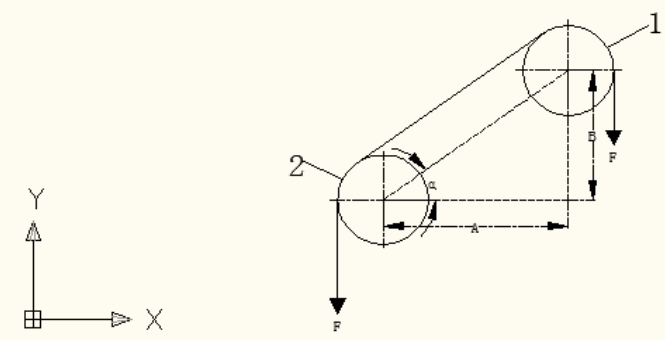

Figure 4: Wheel force diagram two days

1-God wheels, 2-wheel yesterday

Analysis of heaven by force wheels

Because two days is only equivalent to a fixed pulley wheel, 


\section{International Journal of Science and Research (IJSR) \\ ISSN (Online): 2319-7064}

Index Copernicus Value (2013): 6.14 | Impact Factor (2015): 6.391

the wheel on both sides suffered day loads are equalF $=120 \mathrm{~K}-\mathrm{N}$.The two days of separate wheel stress analysis and decomposition of force in the horizontal and vertical directions. Determined force suffered the magnitude and direction of the horizontal and vertical directions each. God suffered wheel force horizontal component:

$$
F_{1 x}=-F \cdot \cos \alpha
$$

Where, $\mathrm{F}$-pumping hanging point of maximum load,

$\mathrm{KN}$;

$\alpha$-The angle between the wheel center wheel 1- two d ays,

$$
\alpha=\arctan \frac{B}{A}
$$

Where, A-two days of the wheel center horizontal dis tance, $\mathrm{mm}$;

B-two days of the wheel center vertical distance, $\mathrm{mm}$. God suffered wheel force vertical component:

$$
F_{1 y}=-F \cdot \sin \alpha-F
$$

Analysis by the day before the wheel force

Similarly, the day before the wheels suffered force hori zontal component:

$$
F_{2 x}=F \cdot \cos \alpha
$$

The day before yesterday suffered wheel force vertical component:

$$
F_{2 y}=F \cdot \sin \alpha-F
$$

\section{Principles Angle Selection}

The smaller of the angle $\alpha$, the rack tipping forward by the force, the more easily inclined toward the direction of the well head; The larger of the angle $\alpha$, the greater the downward force by the rack, the rack higher strength requirements, require better frame material, which increases production costs. Therefore, the angle $\alpha$ not too big nor too small.Here studied the ca-se from the angle $\alpha$ of $30^{\circ}-60^{\circ}$.For analytical studies, two days there is fixed the wheel centerline horizontal distance $\mathrm{A}$, only change the wheel vertical centerline distance $B$, so that when a change in the

\begin{tabular}{|c|c|c|c|c|c|c|}
\hline 夹角 $\alpha / 0$ & $\mathrm{H} / \mathrm{mm}^{2}$ & $\mathrm{~B} / \mathrm{mm}$ & $F_{1 x} / \mathrm{Ka}$ & $F_{1 y} / \mathrm{KW}$ & $F_{2 x} / \mathrm{KW}$ & $F_{2 y} / \mathrm{KWT}$ \\
\hline 30 & 1145 & 660 & -104 & -180 & 104 & -60 \\
\hline 35 & 1145 & 802 & -98 & -189 & 98 & -51 \\
\hline 40 & 1145 & 960 & -92 & -197 & 92 & -43 \\
\hline 45 & 1145 & 1145 & -85 & -205 & 85 & -35 \\
\hline 50 & 1145 & 1364 & -77 & -212 & 77 & -28 \\
\hline 55 & 1145 & 1635 & -69 & -218 & 69 & -22 \\
\hline 60 & 1145 & 1983 & -60 & -224 & 60 & -16 \\
\hline
\end{tabular}
distance B can be achieved which changes t-he angle $\alpha$.Here take A value of $1145 \mathrm{~mm}$. Which changes with the angle component changes as shown in Table 1:

Table 1: Angle changes with each component change
As can be seen from Table 1, as the distance B is increased, the angle $\alpha$ corresponding increase also occurs, heaven horizontal component force decreases wheel 1 , the vertical component increases. The day before yesterday the wheel 2 force component level will be reduced, the vertical force component will be reduced;Two days wheel horizontal component equal and opposite directions, and the vertical force component size varied widely, in the same direction.

\section{The frame model of finite element analysis}

To facilitate rack finite element analysis inthe establishment of the frame geometry, to make a few assumptions:(1) frame body structure is steel, welding rods between each rack reliable, rigid connection;(2)does not consider oblique support, crossbars and uprights centroid without overlap, namely that the beam centroid intersect at t-he point;(3) between the bottom of the s-eat frame work does not occur relative movement and rotation for the fixed bearing.(4) Due to the overall height of the rackis not high, rack suffered wind load is negligible.

Finite Element Analysis of the rack

1)The model established in Solid works import the workbench.

2) Set the material parameters of the rack. Since the material is carbon steel frame, whichever is the elastic modulus $\mathrm{E}$ $=2.07 \times 10^{5} \mathrm{MPa}$, Poisson's ratio $\mu=0.3$, the material yield limit $\sigma_{s}=350 \mathrm{MPa}$.

3)Meshing. Since the frame structure is more complex, which model is automatically divided into tetrahedral mesh.

4)Constraint. Pumping in normal operation, with the bearing between the bottom ofthe rack and rotational relative movement does not occur, so set the boundary conditions are: constrained connection between the frame and the seat, in four locate ons in the rack models treated as fixed b-earing, defined three directions of linear displacement and angular displacement.

5)Load. Since the days of the wheel by the force to $b$ e passed to its respective shaft, so the shaft bearings or bearing suffered across the load size should be $h$ alf days each component of the wheel in the same $d$ irection. Bearing on the magnitude and direction of $t$ he force on that size and direction of the force on $t$ he rack. The level of force applied to the size of the be-aring housing on the wheel bearing to heaven $F_{1 x}$ 12 , horizontally to the left, the vertical component siz $\mathrm{e} F_{1 y} / 2$, a vertically downward direction; the level of force applied to the size of the bearing on the day $b$ efore the wheel bearing is $F_{2 x} / 2$, horizontally to the ri ght, the vertical component $\mathrm{s}-\mathrm{ize} F_{2 y} / 2$, a vertically do wnward direction.

6)Weight. During the analysis needs to considerits own weight for impact of rack stability.

7)To perform static analysis: into the solver, choose sta tic analysis, execution solving.

8)Calculation results and analysis

9)By the finite element analysis results above extracted Angle and total deformation, the maximum equivale nt stress relationship as shown in Table 2: 


\section{International Journal of Science and Research (IJSR) \\ ISSN (Online): 2319-7064}

Index Copernicus Value (2013): 6.14 | Impact Factor (2015): 6.391

Table 2: The angle between the total deformation, max

\begin{tabular}{c|c|c}
\multicolumn{3}{c}{ imum stress relationship } \\
\hline 夹角 $\%$ & 总变形/ $/ \mathrm{mm}$ & 最大等效应力/ $/ \mathrm{MP}^{2}$ \\
\hline 30 & 1.6178 & 108.33 \\
35 & 1.6284 & 109.98 \\
40 & 1.6586 & 113.29 \\
45 & 1.6684 & 114.17 \\
50 & 1.6775 & 114.26 \\
55 & 1.7006 & 114.97 \\
60 & 1.7121 & 121.96 \\
\hline
\end{tabular}

As can be seen from Table 2 , the angle ${ }^{\alpha}=30^{\circ}$, its tota 1 deformation, maximum equivalent stress is minimized; angle $^{\alpha}=60^{\circ}$, its total deformation, maximum equivalen $\mathrm{t}$ stress i-s maximum. As the angle increases, the total deformation, maximum stress is gradually in-creased, an $\mathrm{d}$ the stability of the rack, security will be reduced. Th erefore, the angle between the two days of the wheel $i$ $s$ not too large.

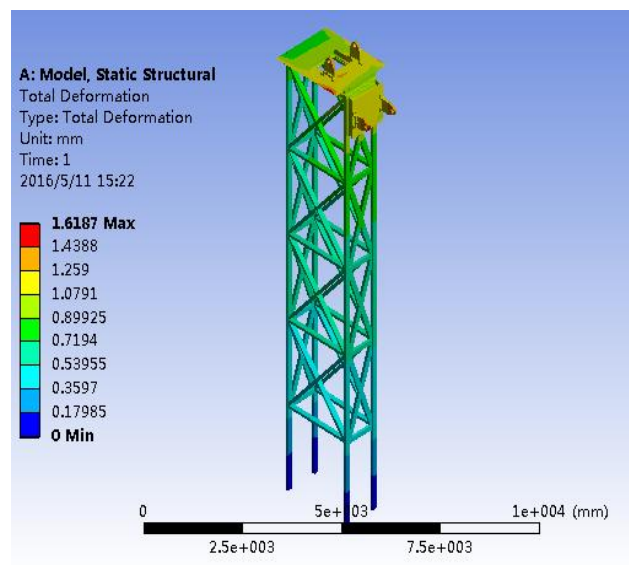

Figure 5: $\alpha=30^{\circ}$ the total deformation cloud

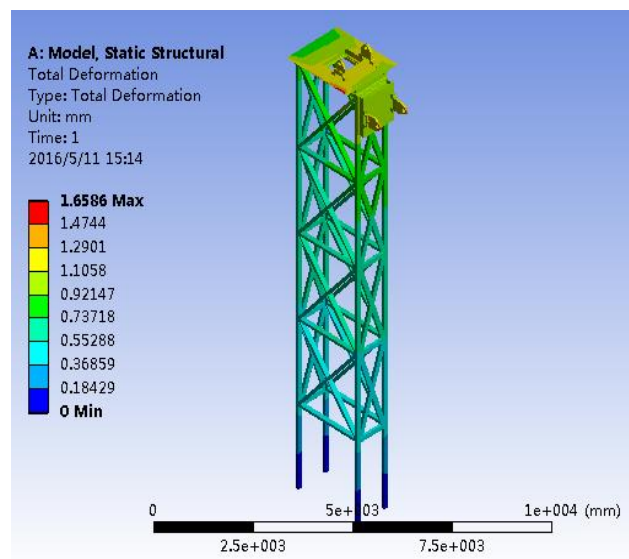

Figure 6: $\alpha=40^{\circ}$ the total deformation cloud

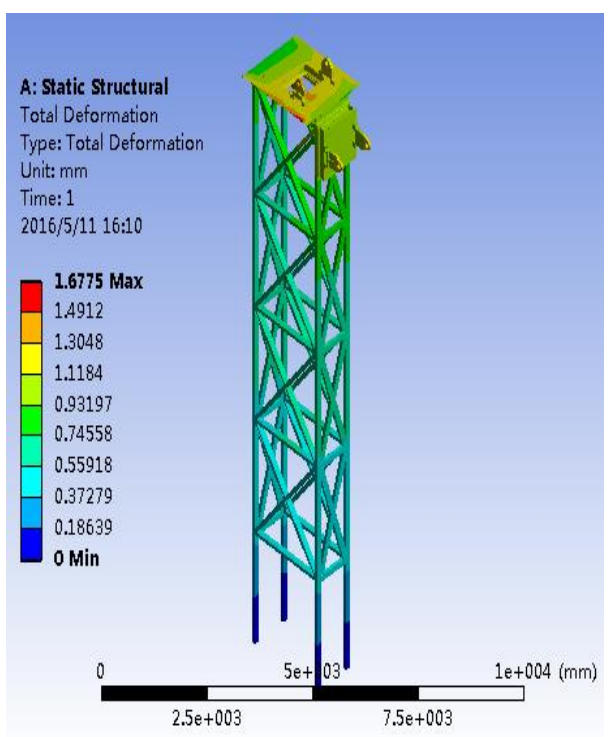

Figure 7: $\alpha=50^{\circ}$ the total deformation cloud

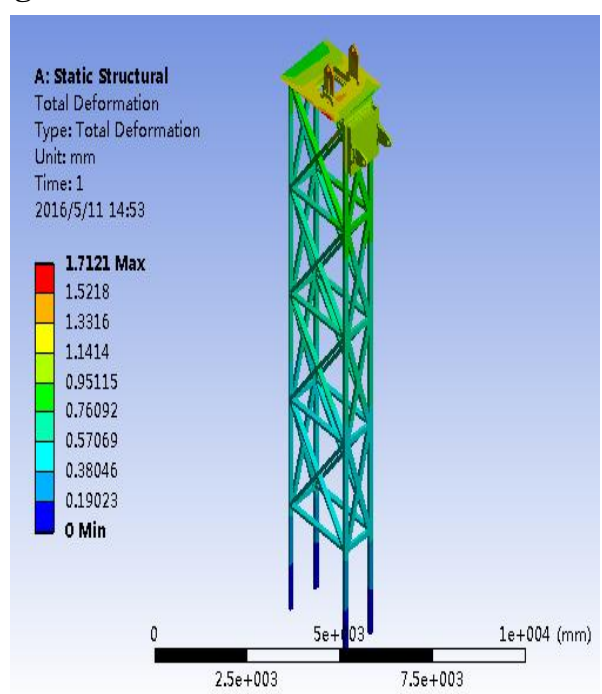

Figure 8: $\alpha=60^{\circ}$ the total deformation cloud

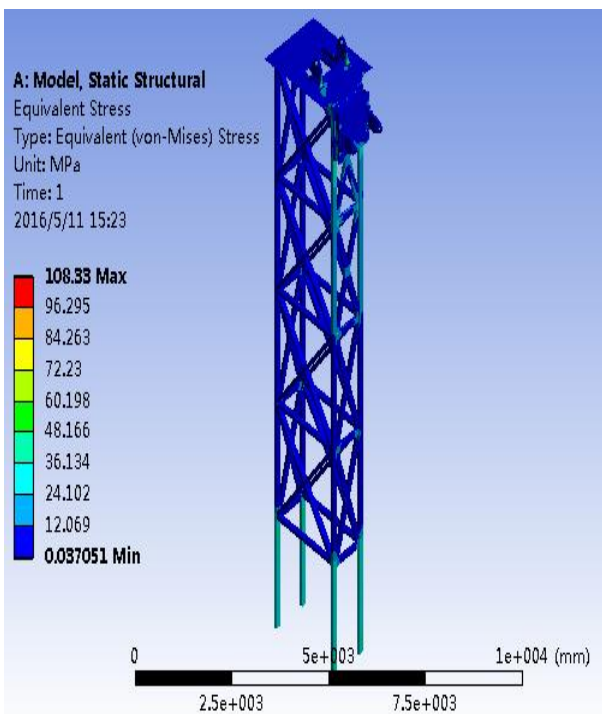

Figure 9: $\alpha=30^{\circ}$ Equivalent stress cloud

\section{Volume 5 Issue 6, June 2016} www.ijsr.net 


\section{International Journal of Science and Research (IJSR) \\ ISSN (Online): 2319-7064}

Index Copernicus Value (2013): 6.14 | Impact Factor (2015): 6.391

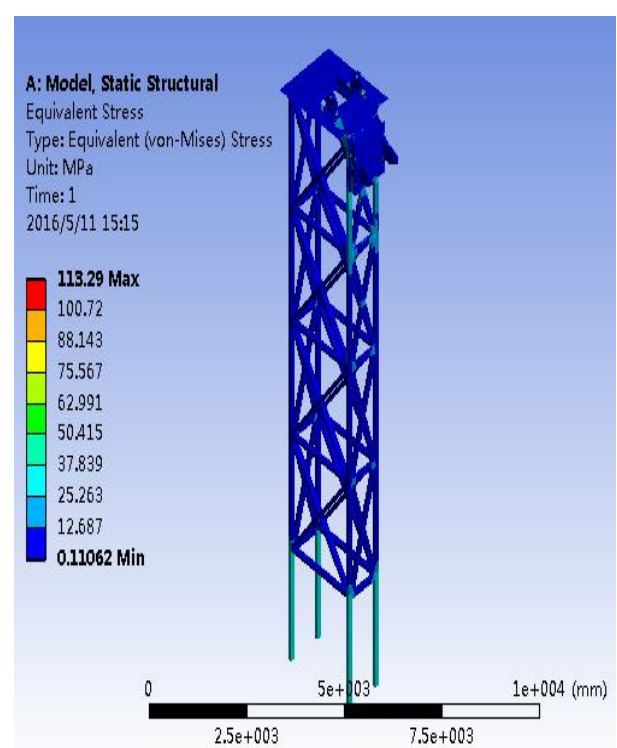

Figure 10: $\alpha=40^{\circ}$ Equivalent stress cloud

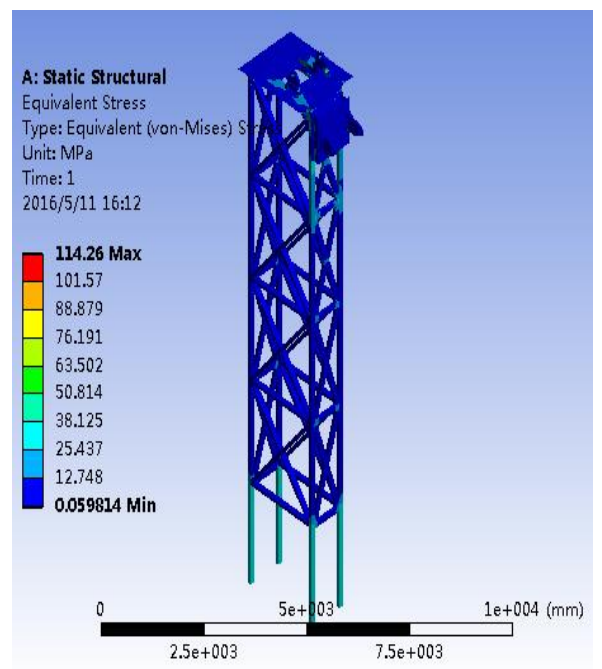

Figure 11: $\alpha=50^{\circ}$ Equivalent stress cloud

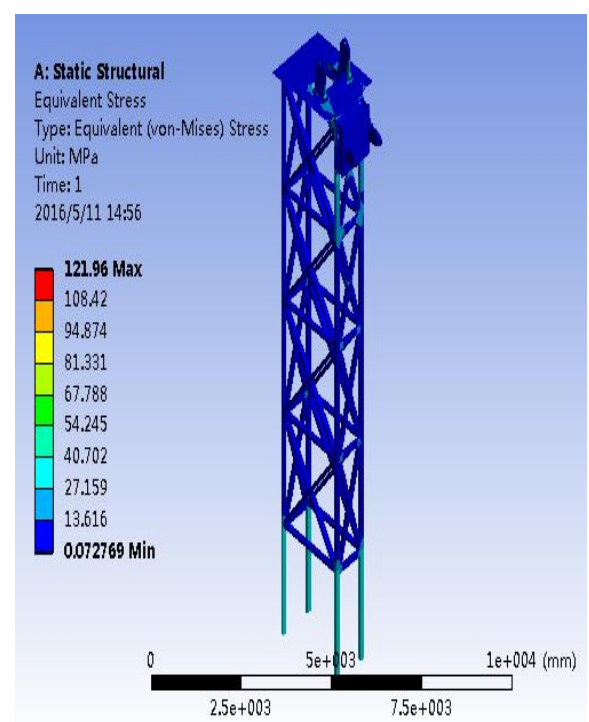

Figure 12: $\alpha=60^{\circ}$ Equivalent stress cloud

\section{Conclusion}

Through analyzing the stress of the frame, structure analysis and finite element analysis, it can be seen that two days the wheels of the centerline of the horizontal angle change will cause the stress of the frame as a whole, the total deformation, the change of the equivalent stress. The angle is small, rack total deformation, the maximum equivalent stress is lesser, the larger Angle, the total deformation, the maxi-mum equivalent stress is larger.With the increase of the angle, the total deformation, the maximum equivalent stress is corresponding to different degrees of increase, the stability of the rack, security will bereduced.Under the same security coefficient, the bigger the Angle between the higher requirements for materials, this will increase the cost of production, is not conducive to saving energy and reducing consumption. So, in order to make the frame safer and better stability, wheel center line of the horizontal angle two days cannot too big, generally around $30^{\circ}$ more appropriate.

\section{References}

[1] ZhangLian-shan. No beam in our country new level of long stroke pumping unit [J]. Journ-al of petrol eum machinery, 1991(9):48-51.

[2] Gu Xin-Yi, ZhouHuan-bo, CuiHuan-yong, e-tc. The development and application of long ring rack pu mping unit $[\mathrm{J}]$. Journal of petroleum machinery, 20 09(5):38-40.

[3] Xiao Wen-sheng,Zhou Xiao-xi, Gu Yu-hong, etc. Li near motor pumping units development $[\mathrm{J}]$. Journal of oil, 2006,(5):112-114

[4] Hou Yong-jun , ZhangQiang. Rack type pumping u nit system dynamics research [D]. Sichuan:southwes t petroleum university, 2014-4-5.

[5] Zhou Qi-wen,, ZhengZhi-jun, JI Lei, etc. To-wer ty pe long stroke pumping unit frame mechan-ics anal ysis [J]. Journal of western exploration engineering, 2011,(5): :51-54.

[6] ANSYS, nIc. ANSYS Coupleed-Field AnalysisGuid e Release 5.4.Third Edition.SAP, IP Inc,1997.

[7] Lu Yi. TatuLeinonen Synthesis and Analysis-of Stro ke-Increasing and Force-Balancing Mechani-sms for Rod Pum-ping Units[J].Journal of EnergyResources Technology ,2002,124:14-19.

[8] About the author:Li Xiao-hua(1989-), male,Sich-uan Province, Chengdu city, sichuan province, Southwes t Petroleum University graduate students. Address: (610500) Xindu district of chengdu in sichuan prov ince.

[9] Fund Project: Ministry of Education Key Laborator y "Oil and gas equipment" (Southwest Petroleum U niversity) funded projects (2014sts03).

[10] Corresponding author: Li Xiaohua. Phone: 1838201 6138.E-mail: 785916209@qq.com 